\title{
Riesgo y biopolítica: réquiem por una pandemia
}

\author{
Risco e biopolítica: réquiem por uma pandemia
}

\section{Risk and biopolitics: requiem for a pandemic}

\author{
(iD) Pablo Pérez Navarro \\ Universidade de Coimbra, Coimbra, Portugal \\ Universidade Federal de Minas Gerais, Belo Horizonte, Minas Gerais, Brasil \\ pabloperez@ces.uc.pt
}

Resumen: La percepción social del riesgo asociado al contagio, la construcción del otro como amenaza y la experiencia social del espacio público durante la pandemia de enfermedad por coronavirus 2019 (COVID-19) resultan de elementos epidemiológicos específicos, entre los que se cuenta el elevado contraste existente entre la relativamente baja mortalidad por infección y la explosiva transmisibilidad del virus. Recurriendo a algunos elementos de la psicología social del riesgo, se argumenta que la vida mediática de esos factores nos sitúa en unas coordenadas biopolíticas similares a las del escenario post-11 de Septiembre, favoreciendo la proliferación de solapamientos, híbridos y alternancias entre el laissez faire neoliberal y las respuestas punitivistas e hiper-securitarias a la pandemia. Como alternativa, se defiende la necesidad de evaluar críticamente las políticas de respuesta en un marco transnacional y radicalmente interpandémico.

Palabras clave: Biopolítica. Percepción del Riesgo. Securitización. Necroliberalismo. COVID-19.

Resumo: A percepção social do risco associado ao contágio, a construção do outro como ameaça e a experiência social do espaço público durante a pandemia de doença por coronavírus 2019 (COVID-19) são consequências de elementos epidemiológicos específicos, inclusive o 
alto contraste entre a relativamente baixa mortalidade da infecção e a explosiva transmissibilidade do vírus. Recorrendo a alguns elementos da psicologia social do risco, argumenta-se que a vida midiática desses fatores nos coloca em coordenadas biopolíticas semelhantes àquelas do cenário pós-11 de Setembro, favorecendo a proliferação de sobreposições, híbridos e alternâncias entre o laissez faire neoliberal e as respostas punitivas e hipersecuritárias à pandemia. Como alternativa, defende-se a necessidade de avaliar criticamente as políticas de resposta em um quadro transnacional e radicalmente interpandêmico.

Palavras-chave: Biopolítica. Percepção do Risco. Securitização. Necroliberalismo. COVID-19.

Abstract: The social perception of contagion-related risk, the construction of the other as a threat, and the social experience of public space during the coronavirus disease 2019 (COVID-19) pandemic stem from specific epidemiological elements, including the high contrast between the relatively low mortality rate due to infection and the explosive viral transmissibility. Drawing on some elements of the social psychology of risk, it is argued that the media life of these factors places us in biopolitical coordinates similar to those of the post-9/11 scenario, favoring the proliferation of overlaps, hybrids, and alternations between the neoliberal laissez faire and the punitive and hyper-security responses to the pandemic. As an alternative, the need to critically evaluate response policies in a transnational and radically inter-pandemic framework is argued.

Keywords: Biosecurity. Risk Perception. Securitization. Necroliberalism. COVID-19.

Data de recebimento: 20/10/2020

Data de aprovação: 03/03/2021 
“La medicina de la epidemia no podría existir sin el suplemento de una policía."

Michel Foucault

“Negar esta vulnerabilidad, desterrarla, sentirnos seguros a expensas de cualquier otro tipo de consideración humana, supone desperdiciar el principal recurso para orientarnos y encontrar una salida."

Judith Butler

\section{Introducción}

En los últimos meses hemos asistido a una proliferación de publicaciones en fast-track, monográficos, libros exprés, foros y blogs personales que discuten el contexto pandémico abierto por la enfermedad por coronavirus 2019 (COVID-19) a partir de sus relaciones con algo llamado "biopolítica". Esto es, con el denso espacio de encuentro entre las humanidades y las ciencias sociales en el que, partiendo de Michel Foucault, se relevan preocupaciones, temáticas y filosofías políticas dispares y que, grosso modo, incluirían la transición de la sociedad disciplinaria a la sociedad del control (DELEUZE, 1992; HARDT y NEGRI, 2002), su expresión superlativa en los estados de excepción (AGAMBEN, 1999), la contraposición con la necropolítica (MBEMBE, 2003), su imbricación con las categorías de inmunidad y comunidad (ESPOSITO, 2005) y su relectura farmacopornográfica (PRECIADO, 2008), por citar tan solo algunos ejemplos.

El nexo parte de una obviedad que, no obstante, merece la pena ser subrayada: las medidas para la mitigación de la pandemia y sus efectos sobre el conjunto del cuerpo social nos sitúan, por definición, en el terreno del conjunto de técnicas de gobierno que, desde finales del siglo XVII europeo, habrían tomado al cuerpo individual como objeto de renovado interés al considerarlo, ante todo, en tanto que elemento vivo -fértil o estéril, joven o anciano, 
Riesgo y biopolítica: réquiem por una pandemia

Pablo Pérez Navarro

sano o enfermo- de una población'. Así lo entendía Foucault (2000, p. 219), al menos, en Defender la sociedad:

[...] la nueva tecnología introducida está destinada a la multiplicidad de los hombres, pero no en cuanto se resumen en cuerpos sino en la medida en que forma, al contrario, una masa global, afectada por procesos de conjunto que son propios de la vida, como el nacimiento, la muerte, la reproducción, la enfermedad, etcétera.

Poco sorprende, pues, que entre las disciplinas que protagonizaron la transición a la que se refiere Foucault (2000, p. 221) ocupase un lugar destacado la medicina moderna que, desde entonces,

[...] va a tener la función crucial de la higiene pública, con organismos de coordinación de los cuidados médicos, de centralización de la información, de normalización del saber, y que adopta también el aspecto de una campaña de aprendizaje de la higiene y medicalización de la población.

En realidad, para Foucault, la medicina no sería tan solo una más entre las disciplinas asociadas al protagonismo creciente del biopoder. Su papel en dicha transición sería, más bien, el un híbrido estratégico y crucial, por la forma en que combina la disciplina del cuerpo/población con unas aspiraciones jurídicas que no asociarían tanto con el emergente biopoder sino, más bien, con las mutaciones del poder soberano. Recordemos que, siempre según Foucault, el derecho moderno implicaba una suerte de repliegue de las formas de soberanía características del Ancien Régime en los nuevos códigos civiles y, sobre todo, penales. Por ese motivo, la dimensión jurídica que, con frecuencia, acompañó a

\footnotetext{
1 Es legítimo preguntarse si toda forma de gobierno, toda medicina y toda ciencia social no implican siempre ya la preocupación por el individuo en tanto que miembro de un conjunto poblacional. Al fin y al cabo, el gobierno del hombre/especie (en los términos de Michel Foucault) o de la vida desnuda (en los de Giorgio Agamben) ha sido puesto en relación con formas de gobierno muy anteriores a las de los modernos Estados-nación, en el entendimiento de que estas se limitarían a exponer "el lazo (derivado de una tenaz correspondencia entre lo moderno y lo arcaico que se encuentra en las más diversas esferas) entre el poder moderno y el más inmemorial de los arcana imperii" (AGAMBEN, 1999, p. 6, mi traducción).
} 
Riesgo y biopolítica: réquiem por una pandemia

Pablo Pérez Navarro

la "medicalización general del comportamiento, de las conductas, de los discursos, de los deseos, etc." combina en la práctica, según Foucault (2000, p. 46), "los dos estratos heterogéneos de la disciplina y la soberanía".

Esta última precisión resulta esclarecedora, en mi opinión, cuando se trata de pensar el papel de las políticas de salud pública en contextos política y epistemológicamente tan convulsos como el que aborda este número temático. Por supuesto, por lo que a las biopolíticas pandémicas se refiere, los escenarios son tan variados como los debates sostenidos en cada uno de ellos en torno a la adecuación y los límites de las respuestas policiales y jurídicas en materia de salud pública, incluyendo cualesquiera restricciones a los derechos de reunión o de movilidad, entre otros. En términos generales, no obstante, resultaría difícil obviar que la preocupación por las relaciones entre políticas de seguridad sanitaria, poderes disciplinarios y formas de poder soberano han adquirido un protagonismo global por completo impensable hace apenas unos meses².

No debe sorprender, por tanto, que las lecturas del contexto pandémico en clave biopolítica sean tan dispares como las formas de entender a esta en cuanto problema y en cuanto campo de análisis. Se abrieron, así, amplias distancias teóricas y políticas entre quienes reaccionaron con cáustico pesimismo ante los estados de excepción reconvertidos en políticas sanitarias, como Giorgio Agamben (2020), quienes casi celebraron el golpe a los fundamentos del neoliberalismo, como Slavoj Zizek (2020), quienes señalaron la intensificación de la biovigilancia tecnológica y digital, como Han Byung-Chul (2020) o Paul B. Preciado (2020), que defendió además la necesidad de regresar a Foucault para entender la radicalización de la presión biopolítica sobre el cuerpo individual (y el apagón digital como alternativa) y quienes insistieron, más bien, en la necesidad de pensar a un tiempo la intensificación de los lazos de

\footnotetext{
20 , para mayor precisión, con anterioridad al breve arco temporal que ligó la respuesta a la crisis del ébola con la de la presente pandemia de COVID-19, vista la forma en que dichas preocupaciones se relacionan con los planes de preparación y seguridad sanitaria global promovidos desde organismos internacionales como la Global Preparedness Monitoring Board (cofundado en mayo de 2018 por el Grupo del Banco Mundial y la Organización Mundial de la Salud [OMS] a raíz de la epidemia de ébola de 2014-2016) (GPMB, 2019a, 2019b).
} 
vulnerabilidad compartida y su desigual distribución "en el interior de las zonas pandémicas" (BUTLER, 2020, p. 60). Nada más lejos, por fortuna, de las preocupaciones que guían el presente artículo que la pretensión de sistematizar o responder a cualesquiera de estos y otros muchos análisis que, promisoriamente, han desbordado la rígida temporalidad académica en los últimos meses. Su relación con dicho campo se limita, más bien, a compartir una preocupación implícita en muchas de esas discusiones, a saber, la de que las políticas de contención, mitigación y supresión de la pandemia de COVID-19 constituyen un capítulo propio en el desarrollo histórico de las preocupaciones que ocupaban del pensamiento de Foucault en sus discusiones en torno al término "biopolítica".

Dicha preocupación operará aquí, pues, como punto de partida para explorar la forma en que las respuestas gubernamentales a la pandemia de COVID-19 se relacionan con el interregno a cuya conquista se dirige toda epidemiología (y toda biopolítica), a saber: la distancia temporal, espacial y cognitiva que separa la suerte del cuerpo individual de la del conjunto de la población. Con ese fin abordaré, en primer lugar, la percepción del riesgo asociada a una enfermedad de alta transmisibilidad y relativamente baja mortalidad. Me interesan, en particular, las paradojas y aparentes contradicciones propias de la comunicación de los riesgos pandémicos y su impacto sobre aspectos como la construcción del otro como amenaza y nuestra relación con los espacios públicos, así como la forma en que estos factores confluyen en la transición de las narrativas y tecnologías securitarias del escenario post-11 de Septiembre con las del mundo post-COVID-19. Para finalizar, defenderé la adopción de una perspectiva crítica interpandémica que permita resistir tanto a los avances de la agenda neoliberal como la securitización y el punitivismo crecientes de las respuestas a la pandemia. 


\section{“Gripezinha": un experimento viral}

Permítaseme comenzar dicha tarea con un experimento mental o, si queremos, viral. Supongamos que, por causas naturales, deliberadas o accidentales, se liberase un virus desconocido para el cuerpo humano y que, en un contagio al azar, tuviese una cuarta parte de la capacidad letal de la gripe común. Es decir, que tuviese una tasa de mortalidad por infección en torno al 0.025\%33. Supongamos, además, que cada persona contagiada lo transmitiese de media a otras 15, como sucede con el sarampión, en lugar de las 2 o 3 que se estiman de media para el virus del síndrome respiratorio agudo severo tipo-2 (SARS-CoV-2). La pandemia resultante resultaría, a pesar de la baja letalidad, casi imposible de contener. La inmunidad de grupo, dada su alta transmisibilidad y en ausencia de inmunidad previa, se aproximaría peligrosamente al conjunto de la población. Si la enfermedad fuera, además, de curso rápido, los servicios sanitarios y funerarios colapsarían en un breve espacio de tiempo. En esas condiciones, la "gripezinha" de Jair Bolsonaro podría terminar con la vida de, aproximadamente, unos 2 millones de personas. En el proceso, la pandemia provocada por un virus de baja letalidad y alta transmisibilidad distribuiría rápidamente sus efectos sobre el conjunto del cuerpo social. Por supuesto, estos divergirían en función de factores tales como la capacidad de los sistemas de salud para responder a la presión adicional, la respuesta más o menos temprana por parte de gobiernos y organismos internacionales o el balance entre los aspectos sanitarios y punitivos de las medidas adoptadas para la mitigación de los efectos de la pandemia. Cabe identificar, no obstante, algunos aspectos en los que resultaría difícil evitar un notable impacto biopolítico.

El paradójico contraste entre transmisibilidad y letalidad tendría, en primer lugar, efectos singulares al nivel de la percepción del riesgo asociado al contagio. La idea de que una enfermedad

3 Uso como referencia la tasa de mortalidad por infección para la gripe el 0,1\%, ampliamente referido por los medios como punto de referencia frente a la pandemia de COVID-19 (véase como ejemplo LLANERAS, 2020). 
más débil que una gripe común pudiese generar tal acumulación de muertes resultaría en exceso contraintuitiva. En la práctica, cualquier contacto con el virus tendería a ser interpretado como una grave amenaza vital. Se produciría, así, un divorcio entre la percepción técnica y la pública del riesgo asociado al contacto individual con el virus, de acuerdo con un fenómeno común en los contextos de riesgo sanitario. Así lo explica, por ejemplo, Milena Stanojlovic (2015, p. 99), especialista en comunicación sanitaria:

La percepción pública puede diferenciarse de la percepción científica de riesgo, porque no se basa solamente en datos objetivos. Más bien, los marcos de referencia para la percepción pública de riesgo suelen fundamentarse en criterios subjetivos o en fuentes no científicas y no siempre tan fiables, tales como las decisiones políticas, las creencias dominantes y la información proporcionada por los medios de comunicación, que en medida significativa condicionan la percepción real sobre el riesgo, incluso más que la evaluación científica basada en los estudios empíricos.

La inflación sería, pues, inevitable, si bien el grado de la inflación de la percepción del riesgo dependería de las estrategias mediáticas de comunicación de los riesgos o, con mayor precisión, de la relación establecida entre estas y la capacidad para su decodificación por parte de diferentes segmentos sociales (asílo enfatizan, en particular, DELICADO y GONÇALVES, 2007; KASPERSON, 2005). Se concretaría con ello, además, un efecto bien conocido por la psicología del riesgo (y las compañías de seguros), según la cual la percepción de riego asociada a un evento catastrófico, tal como la posible rotura de una presa, guardaría una relación más directa con la percepción subjetiva de sus posibles efectos devastadores por parte de la población vecina que con los resultados de cualquier análisis técnico de la resistencia de sus materiales (véase LIMA, 1998). Si sumásemos a este efecto, además, el duelo por las víctimas y la adopción de medidas de alto coste psicológico, como los confinamientos obligatorios, se podría generar una auténtica tormenta perfecta a nivel de la salud mental, 
cuyos efectos trascenderían ampliamente el plano individual en formas diversas de socialización del trauma. En el caso límite, esto es, si los niveles de ansiedad, estrés y sufrimiento individual sobrepasaran una determinada masa crítica, serían de esperar transformaciones políticas, institucionales y jurídicas que podrían afectar a varias generaciones. Es lo que sucede, tal y como apunta la metáfora de uso común en tiempos pandémicos, en los contextos de guerra. El horizonte social del miedo sería, pues, profundamente biopolítico.

El contraintuitivo contraste entre baja letalidad y alta transmisibilidad conllevaría, además, una segunda inflación: la de la percepción del otro como amenaza. Cuando todo contacto social es leído como una amenaza de contagio y este lo es, a su vez, de muerte, todo encuentro en el espacio público lo es con un potencial asesino. El espacio público sufriría, como consecuencia, una completa transfiguración ${ }^{4}$. Sin duda, en las condiciones propuestas, cada contagio sería potencialmente letal en su dimensión global. Este hecho conllevaría, por sí solo, una gran responsabilidad colectiva. En la práctica, no obstante, esta se haría acompañar por un miedo al encuentro que, en su inmediatez, trascendería con creces cualquier preocupación por el bienestar colectivo: el miedo al virus y el miedo al otro serían por completo indistinguibles entre sí.

Combinados, estosfactores podrían favorecer todo tipo de derivas autoritarias cuyo apoyo social rayaría, sin grandes dificultades, en lo totalitario. El miedo justificaría los medios. Al mismo tiempo y, por así decirlo, paradójicamente, la negativa a implementar respuestas estatales adecuadas encontraría una conveniente coartada en la baja letalidad individual asociada a una pandemia paradójica en el sentido descrito: ¿Para qué preocupar a los mercados, argumentaría, si la amenaza es cuatro veces más débil que una simple gripe? Se perfilaría así el ala negacionista del espectro neoliberal, fiel al imperativo de la protección de la esfera privada a costa del bienestar del conjunto de la población. A primera vista, las derivas autoritarias y la dejación neoliberal de funciones podrían parecer extremos incompatibles.

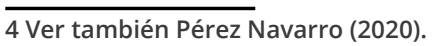


Riesgo y biopolítica: réquiem por una pandemia

Pablo Pérez Navarro

En la práctica, no obstante, el evento pandémico podría favorecer todo tipo de superposiciones, alternancias e híbridos entre ambos. Las respuestas tardías, las limitaciones de los recursos públicos, y la negativa a poner los recursos privados al servicio de la salud pública durante la emergencia sanitaria, en particular, abrirían paso a todo tipo de estrategias de compensación autoritaria. A la postre, la paradójica pandemia se convertiría en una adecuada metáfora del ascenso de las nuevas extremas derechas a nivel global, tan duchas en el laissez faire neoliberal como en la vigilancia autoritaria de las fronteras físicas y morales del orden social.

\section{Medios y epidemiólogos: del riesgo a la biopolítica}

A priori, esta dimensión paradójica del experimento viral propuesto parece encontrarse ausente 0 , al menos, muy mitigada en el caso del COVID-19. Para empezar porque, en condiciones "normales", cada persona transmite el virus a otras dos o tres, muy lejos de las quince de enfermedades como el sarampión. Por lo que a su letalidad se refiere, parecería igualmente fuera de toda duda el hecho de que, a nivel individual, el contagio de COVID-19 no es menos peligroso que el de la gripe común. En principio, solo un virus mucho más agresivo que cualquier gripe podría alcanzar tasas de mortalidad como las del 10\% o 12\% en España e Italia, respectivamente (BENNHOLD, 2020); o las del 6,3\% que se divulgaban en Brasil a finales de mayo (VALENTE, 2020) ${ }^{6}$, por citar solo algunos ejemplos con gran presencia mediática durante la primera ola de la pandemia7. Cabría preguntarse, no obstante, tomando las precedentes consideraciones como guía y fuente de inquietud, si podría existir algún tipo de inflación de la percepción el riesgo en juego en nuestra relación con el COVID-19. Más en

\footnotetext{
5 El número básico de reproducción (también conocido como ratio reproductiva básica, o R0) del COVID-19 se sitúa en torno al 2,8 frente 1,5 de la gripe común y el 15 del sarampión.

6 Posteriormente reducida en torno al 3,5\%.

$7 \mathrm{Mi}$ atención especial al sur de Europa y, en particular, a España, por un lado, y a Brasil, por el otro, no se debe tan solo a su lugar destacado como epicentros epidémicos en diferentes periodos. Me interesa también su carácter excepcional por lo que a las narrativas políticas de la pandemia se refiere, con el gobierno de Jair Bolsonaro como exponente necroliberal, de un lado, y la militarización del espacio público y aplicación masiva de multas mediante la represiva ley mordaza en España como símbolo de la securitización de las medidas de contención, por el otro.
} 
concreto, ¿podría la interpretación de datos mediáticos como los citados favorecer algún tipo de inflación de la percepción del riesgo asociado al contagio? ¿Y en qué medida podría esa hipotética inflación aproximarnos a las coordenadas biopolíticas de nuestro experimento viral?

Para responder a esas preguntas conviene recordar, en primer lugar, que las tasas de mortalidad que con mayor frecuencia se repiten en los medios corresponden a los casos testados y confirmados. Es lo que se conoce, en términos epidemiológicos, como "mortalidad por casos". La precisión es importante ya que, durante la primera ola, dicho dato restringe prácticamente su sentido a la evolución de pacientes graves y hospitalizados. Especialmente en contextos marcados por la escasez de medios para la realización de pruebas diagnósticas. Así calculada, la tasa de mortalidad por casos se dispara muy significativamente sobre la tasa de mortalidad real o por infección (LIPSITCH et al., 2015). Esto es, sobre la mortalidad asociada al contagio aleatorio por el virus.

Se ha señalado, en ocasiones, que el énfasis en la mortalidad por casos y la consiguiente inflación en la percepción del riesgo tendrían la ventaja de no enviar falsas sensaciones de seguridad al conjunto de la población ni, en particular, a sus segmentos más vulnerables (KOBAYASHI et al., 2020). Poca atención se ha prestado, no obstante, al impacto que dicho foco pueda tener sobre el conjunto de la población. Si pretender con ello sustituir a las investigaciones empíricas que se puedan conducir al respecto, la siguiente comparación puede resultar útil, me parece, como aproximación intuitiva a ese problema.

Supongamos que, al inicio de una temporada de gripe estacional, los medios centrasen la atención en la proporción entre hospitalizaciones y muertes derivadas de la gripe común que, según los datos ofrecidos por organismos como el Center for Disease Control and Prevention (CDC, 2020a), de Estados Unidos (EE.UU.), y el Health Protection Surveillance Centre (HPSC, 2018), de Irlanda, se encuentran justamente entre el $5 \%$ y el $10 \%$. Sin duda, ese foco en el marco hospitalario tendría un importante impacto 
en la ampliación de la percepción del riesgo asociado al contagio de la gripe estacional. La inercia histórica de naturalización de los efectos de la gripe estacional se vería, cuanto menos, afectada. Los datos serían fidedignos $y$, a la vez, por completo ajenos a los de la experiencia de la gripe extramuros que se habría visto, no obstante, modificada bajo su influencia. El abismo epistemológico sería incluso cuantificable, al menos, por lo que a las cifras de mortalidad se refiere: la citada tasa de mortalidad "hospitalaria" multiplica por más de cien a la mortalidad por infección de la gripe común, tal y como esta se calcula para un contagio aleatorio. De esa forma, incluso una enfermedad con una mortalidad por infección tan "baja" como la gripe común (a pesar de ser pésima candidata para despreciar, por comparación, la capacidad letal de cualquier enfermedad, pues es responsable por hasta 650.000 muertes en los escasos 5 meses que dura la estación gripal), su recorte hospitalario podría amplificar de formas imprevistas los procesos sociales de percepción del riesgo. Se confirmaría así, de paso, por la vía de la vida mediática de la idiosincrasia estadística hospitalaria, el poder atribuido por Foucault (1973, p. 19) a los hospitales para distribuir los efectos de la enfermedad gracias a una capacidad diagnóstica que "comunica la enfermedad y la multiplica hasta el infinito".

Sin duda, el caso del COVID-19 no es equiparable, por lo que a su impacto se refiere, a la de cualquier otra enfermedad viral respiratoria. No obstante, la relación entre las cifras de mortalidad por casos (indiscutibles protagonistas mediáticas al paso de la curva pandémica por los diferentes países) y por infección (confinada, por lo general, a las publicaciones académicas) del COVID-19 se encuentra, en realidad, muy próxima a la desproporción citada. Así lo explicaba, a inicios de marzo de 2020, Adolfo-García Sastre, especialista en virus respiratorios y codirector del Instituto de Salud Global y de Patógenos Emergentes en la Escuela de Medicina Icahn Mount Sinai, de Nueva York, cuando atajaba los debates sobre las diferentes tasas de mortalidad en diferentes contextos señalando que la tasa de mortalidad por infección del SARS-CoV-2 
era "la misma" en todos los países, y que se situaría en torno al 0,1\% y el 0,3\% (FUENTECILLA, 2020). Esto es, bastante próxima a la de la gripe común y hasta 100 veces inferior a las mediáticas tasas de mortalidad por casos. En la misma línea apuntaron, con variaciones, multitud de estudios publicados durante los meses siguientes, comenzando por los modelos de contención divulgados a mediados de marzo por el Imperial College de Londres, que partían de una mortalidad por infección del 0,9\% (FERGUSON et al., 2020). Del mismo Imperial College proceden también los cálculos que reducían dicha tasa al 0,66\% (VERITY et al., 2020), a partir de los datos de la provincia china de Hubei. Desde la London School of Hygiene and Tropical Medicine (LSHTM), por su parte, extrapolando los datos de las particularidades del escenario del crucero Diamond Princess, reducían la mortalidad por infección hasta al 0,37\% (RUSSELL et al., 2020), en coincidencia con el COVIDCase-Cluster-Study, otro estudio desarrollado en una población acotada y de alta prevalencia (en este caso, la localidad de Gangelt, Alemania) (STREECK et al., 2020). El Centre of EvidenceBased Medicine de la Universidad de Oxford, a su vez, teniendo en cuenta el conjunto y la evolución de los estudios disponibles hasta la fecha, estimó una mortalidad por infección entre el 0,1\% y el 0,4\% (CEBM, 2020), mientras que el CDC (2020b) apunta más bien, desde finales de mayo y con fines de planificación, a una letalidad menor al $0.4 \%$, y ello solo para los casos sintomáticos -lo que conllevaría una letalidad por infección, para el conjunto de la población, significativamente menor.

Dicho de otra forma, las tasas de mortalidad divulgadas en los medios durante los primeros meses de evolución de la pandemia en países como Italia o España serían de un orden hasta 5 veces superior a la tasa de mortalidad real (esto es, por infección) del COVID-19. Algo muy similar se podría decir sobre datos como el 3,5\% de mortalidad contabilizado desde junio en Brasil, o el similar 3,4\% difundido por la Organización Mundial de la Salud (OMS) como media global de la tasa de mortalidad. No porque esos datos sean falsos, pues no lo son, sino porque se refieren a una tasa 
de mortalidad por casos cuyo foco hospitalario impide establecer cualquier tipo de relación informativa con el riesgo realmente asociado a un contagio aleatorio. La vida mediática de esos datos, sin embargo, tiene una obvia capacidad para convertirse en uno de los principales motores de la inflación de la percepción social de riesgo, con efectos directos sobre la percepción del otro como amenaza y la experiencia del espacio público. En el mejor de los supuestos, la espectacularización mediática de la idiosincrasia hospitalaria y el protagonismo extramuros de la mortalidad por casos podrían tener un efecto positivo sobre el seguimiento de las políticas de prevención. Esto es, suponiendo que desproporciones como las citadas no sirviesen más bien para provocar reacciones de desafección, para alimentar el arsenal discursivo de las respuestas negacionistas y para aproximarnos más, en el proceso, a las inquietantes coordenadas biopolíticas de nuestro experimento viral.

\section{4}

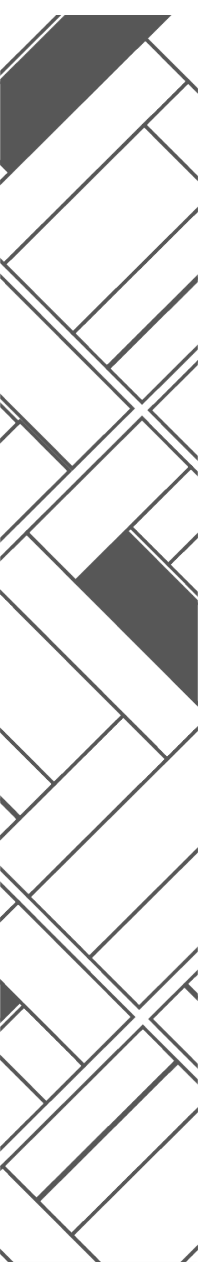

\section{Necrológicas interpandémicas}

A pesar de su relativamente baja tasa de mortalidad, la alta transmisibilidad del COVID-19 es responsable por una letalidad sensiblemente superior a la gripe común. Mientras escribo este párrafo, a mediados de octubre de 2020, las cifras de muertes se aproximan ya, en Europa, al doble de las 152.000 que causó la estación de gripe de 2017 (NIELSEN et al., 2019). Su tasa de hospitalizaciones simultáneas es, además, muy superior a la de la gripe estacional, y ha causado estragos en escenarios que combinan factores de riesgo y confinamientos prolongados, como las residencias de ancianos, donde se habrían producido en torno al $40 \%$ y el $60 \%$ de las muertes totales de países como EE.UU., España, Francia, Bélgica o Canadá (THOMPSON et al., 2020). La única comparación en la que el COVID-19 se manifiesta más benigno que la gripe común parece ser la de sus efectos en la infancia y adolescencia, toda vez que la gripe estacional causa 
entre 10.000 y 1.000 .000 de muertes anuales, según los estudios dirigidos por la OMS (PAGET et al., 2019), mientras que el SarsCoV-2 apenas conlleva mortalidad infantil asociada (SINHA, 2019). La gravedad de su impacto global pertenece, lejos del alcance retórico de cualquier negacionismo, al orden de lo catastrófico.

En su radical abstracción, no obstante, las infinitas variaciones de los mapas y curvas epidemiológicas difundidas por los medios resultan tan ominosas como, a la postre, ininteligibles. Desprovistas de cualesquiera puntos de referencia, como las "personas-puntito" de los modelos epidemiológicos (CARRARA, 2020), el crecimiento exponencial de las curvas se ofrece como centro retórico de un sistema semántico autista y autocontenido en sí mismo. La ubicuidad mediática de tales mapas conlleva, además, la herida de una ausencia, a saber, la de los centenares de mapas pandémicos que nunca se abrieron paso hasta los titulares de los grandes medios de comunicación. Podríamos destacar, entre estos, a los 2 millones de nuevos contagios y las cerca de 800 mil muertes evitables atribuibles al sida cada año (ONUSIDA, 2020), el del 1,5 millón de la tuberculosis, las más de 400 mil de la malaria, los 8 millones de la industria tabacalera, los 7 millones de muertes anuales atribuibles según la OMS a la contaminación atmosférica o el 1,3 millón de los accidentes de tráfico (OMS, 2014, 2017, 2019, 2020), entre otros ejemplos posibles.

Vistos el solipsismo y el monopolio mediático de los regímenes de representación de la pandemia de COVID-19, la pregunta por los motivos por los que esta abre la puerta a todo tipo de respuestas de excepción, mientras que otras pandemias y causas de muerte forman parte de la más trivial cotidianeidad necropolítica, por usar el término de Mbembe (2003), dista mucho de poder ser soslayada bajo el peso del duelo por el proceso pandémico. De otro modo, la pandemia de COVID-19 podría convertirse en un velo cognitivo más extendido sobre las jerarquías económicas, raciales, sexuales y de género sobre las que descansan los regímenes de representación $y$, sobre todo, los de sus ausencias, con los que nos enfrentamos otras pandemias y causas de muerte. La pregunta parece tanto 
más urgente, además, cuando las medidas para la supresión y mitigación del COVID-19 interactúan con ellas de formas que distan de ser evidentes para configurar, en sentidos que apenas comenzamos a comprender, un complejo escenario de pandemias colaterales.

Cierto es que el término "pandemia colateral" se ha reservado, hasta la fecha, a los efectos letales de las limitaciones en el acceso a los servicios sanitarios básicos y, en especial, de urgencias durante los periodos de confinamiento (SØREIDE et al., 2020). Ampliar su uso a una perspectiva interpandémica requeriría tener en cuenta, en primer lugar, el efecto letal, en sentido metafórico y real, de las respuestas a la pandemia sobre las comunidades que más intensamente sufren ya su dimensión estrictamente viral. Es el caso de las desplazadas económicas y las refugiadas, que han sufrido un recrudecimiento de su exclusión del mercado laboral en multitud de países (OECD, 2020), junto con los efectos directos del cierre de fronteras y de la interrupción de los procedimientos de asilo (ACNUR, 2020). Su situación es paralela a la que sufren en las grandes periferias urbanas, tanto en Europa como en el sur global, donde a la falta de infraestructuras y recursos sanitarios básicos se le ha sumado una intensificación de la presión policial y militar. Podemos citar, en ese apartado, la denuncia de cientos de colectivos de pueblos originarios América Latina, que sufren el aumento de la violencia arbitraria, machista y homofóbica como resultado de la presencia militar en países como Bolivia, Colombia, o Perú, entre otros (CONAIE, 2020), así como el caso de las favelas de Río de Janeiro, donde la letalidad de las operaciones policiales durante los primeros meses del aislamiento social aumentó hasta el 40\% (ISP, 2020). El porcentaje coincide, casualmente, con el porcentaje de aumento en las cifras de asesinatos de la población travesti en todo Brasil (ANTRA, 2020), síntoma de la falta de alternativas y la mayor exposición a la violencia para quienes dependen del espacio público para trabajar, como es el caso de muchas trabajadoras del sexo. 
La ampliación del significado de la pandemia colateral debería incluir, además, las consecuencias directas del despliegue de las medidas biosecuritarias sobre diferentes conjuntos de la población, tales como la reducción de la calidad y de la esperanza de vida de los 22 millones adicionales que entrarán en situación de pobreza extrema según la Comisión Económica para América Latina y el Caribe (CEPAL, 2020) de la Organización de las Naciones Unidas (ONU), tan solo en esas regiones. Igualmente necesario sería tomar en cuenta el 1 millón de muertes maternas e infantiles que se esperan como resultado de la disrupción de las cadenas de suministros en los países del Sur Global (FORE, 2020), como recuerda el Fondo de las Naciones Unidas para la Infancia (United Nations International Children's Emergency Fund [UNICEF]) en un informe reciente, y que se sumarían al 1 millón de muertes adicionales que se esperan a causa de la tuberculosis en escenarios de 3 meses de confinamiento (STOP TB PARTNERSHIP, 2020). Sin olvidar el coste directo de los confinamientos en términos de salud mental, incluyendo el aumento en las cifras de suicidios (TORALES et al., 2020), las cifras de la violencia de género asociadas a los escenarios de confinamiento obligatorio (BRADBURY-JONES y ISHAM, 2020), ni los efectos de la interrupción de programas y la interrupción de las políticas de prevención, detección y tratamiento del VIH-sida en multitud de contextos.

En una perspectiva interpandémica, ninguno de estos datos bastaría, por sí solo, para valorar la adecuación, la proporcionalidad o el éxito de ninguna medida concreta de respuesta a la crisis sanitaria. $\mathrm{Ni}$, muchísimo menos, para abogar por una igualmente letal ausencia de respuestas. Tomados en conjunto, no obstante, las víctimas colaterales de las respuestas nacionales y globales al COVID-19 demandanunanálisis deriesgosybeneficios paramedidas tales como los confinamientos obligatorios, la militarización de las respuestas sanitarias, la securitización creciente de las fronteras, o la configuración y extensión de los periodos de aislamiento social cuya resolución puede ser mucho más compleja de lo que parecen dispuestas admitir las narrativas hegemónicas en materia de 
seguridad sanitaria. Como mínimo, la complejidad del escenario colateral constituye una fuente inagotable desasosiego ético y político, que nos obliga a confrontar las retóricas que acompañan a las respuestas políticas a la pandemia de COVID-19, desde las más prudentes y responsables hasta las más belicistas, con un horizonte crítico y solidario radicalmente interpandémico.

\section{Réquiem: a modo de conclusión}

En un mundo en el que unas pandemias importan más que otras, las relaciones de interdependencia y solidaridad ceden fácilmente ante el aislamiento y el pánico, favoreciendo todo tipo de derivas punitivas y autoritarias para la defensa del bien común, del orden y de la salud públicas: cientos de miles de cámaras de reconocimiento facial en las nuevas "ciudades inteligentes", como Moscú o Pequín (KITCHIN, 2020); aplicaciones de rastreo con graves problemas de transparencia en el manejo de datos en países como Croacia, Bulgaria, Eslovaquia, Dinamarca, Hungría, Rumanía, Lituania, China o Corea del Sur (para el contexto europeo, véase FRA, 2020); más de un millón de elevadas multas aplicadas en España mediante la represiva "ley mordaza" durante el periodo de confinamiento obligatorio (LÓPEZ-FONSECA, 2020); segregación por sexos de los espacios públicos en Perú, Panamá y Colombia, con nefastas consecuencias para la población trans (PEREZ-BRUMER y SILVA-SANTISTEBAN, 2020); licencias para matar durante los confinamientos en las operaciones policiales de Filipinas (EL PAÍS, 2020) y El Salvador (GARCÍA, 2020); amenazas a la libertad de prensa en Polonia y Hungría; prohibición de las interacciones sociales entre no convivientes o más en los espacios públicos y privados del Reino Unido (HANCOCK, 2020)... En la nueva excepcionalidad, solo se podría pecar por defecto.

Con frecuencia, los argumentos que acompañan esas y otras medidas de contención recuerdan, con su ceguera frente a sus víctimas colaterales y a los riesgos autoritarios, a las incursiones 
bélicas en nombre de la exportación de la democracia o de la guerra contra el terrorismo. En ese sentido, el evento pandémico nos situaría en un escenario extrañamente similar al descrito por Judith Butler (2006) tras los atentados del 11 de Septiembre, cuando el duelo selectivo por algunas víctimas del terrorismo se convirtió en la disculpa para la reactivación de los circuitos de violencia en los que se verían envueltas otras. Intensificando, en el proceso, el poder de los presupuestos nacionalistas, raciales y de clase con los que la comunidad "atacada" se define a símisma. En aquella ocasión, como apuntó a su vez Jean Baudrillard (2002), los paradigmas securitarios fueron posibilitados por la dimensión hiperreal de los atentados, esto es, por el impacto de una transmisión global a tiempo real que saturó el espacio de la representación hasta sustituir por completo al evento "real". En ese sentido, como lo expresaría por su parte Jacques Derrida (2003), el acontecimiento terrorista se habría emancipado del evento real hasta convertirse en una cita de sí mismo, una copia de una copia, a una distancia respecto al evento original que no haría sino aumentar con cada repetición mediática. A la postre, sería justamente esa vida hiper-mediática del evento, con su delimitación selectiva de los duelos audibles en la esfera pública (como nos ayudó a pensar BUTLER, 2006) la que impulsó las respuestas bélicas e imperialistas, la multiplicación de las víctimas colaterales, los recortes de derechos en nombre de la seguridad nacional y la transición de las paradigmas securitarios como consecuencia de la inflación de la percepción del riesgo de que en cualquier barrio se produjera la conversión, por contagio (como nos advirtió BAUDRILLARD, 2002) de un nuevo terrorista.

Por su parte, el evento COVID-19 resulta indisociable de una retransmisión globalizada y a tiempo "real" sin precedentes. La inteligibilidad social de la pandemia depende, justamente, de su construcción como acontecimiento mediático, facilitada por la evolución reciente de los dispositivos de seguimiento y preparación ante las alarmas epidémicas. En el proceso, con cada mapa y recuento de muertes, la representación de la pandemia se disemina geográfica y temporalmente, como si de un atentado o una caída de 
las Torres ubicua y en slow-motion se tratase. Ahora bien, Baudrillard (2002) subrayaba la dimensión arquitectónica involucrada en el simbólico suicidio de las Torres, que pudimos contemplar desde todos los ángulos externos posibles. A diferencia de aquellas, la arquitectura de la curva pandémica no ofrece más perspectiva que la interior. Es esa relación de interioridad la que permite que se nos adjudiquen, a priori y de forma innegociable, todos los papeles del acontecimiento: el de oficinistas que aguardan el impacto de la curva que se aproxima con la parsimonia de un tsunami, las pasajeras que, negada la posibilidad de la despedida física, lo hacen mediante mensajería móvil o quienes rompen las cuarentenas saltando desde las ventanas. Sin olvidar, por supuesto, el de bio-terroristas bajo amenaza permanente de detención indefinida.

Esta última comparación se sitúa, quizás, en la órbita de las más pesimistas entre las lecturas biopolíticas del contexto pandémico con las que se abría este artículo. Cuestión de grados, sin duda, y de perspectiva; pero también de las latitudes genéricas, raciales y de clase en que nos encuentren los próximos tiempos. No es casual, en ese sentido, que los signos más vitales de resistencia durante los toques de queda y los periodos de confinamiento obligatorio se encontrasen en el movimiento Black Lives Matter, o en sus sinergias con las luchas antirracistas en muchas ciudades de Europa y Latinoamérica, pese al silencio y la incomprensión de amplios sectores de la izquierda.

Entretanto, con nuestro apoyo tácito, o sin él, las políticas globales de seguridad sanitaria se alzan como digno sucesor del poder retórico de la guerra contra "el eje del mal", ayudadas por el desarrollo de todo tipo de tecnologías biosecuritarias. No resulta extraño, en ese escenario, que la creciente sofisticación de los sistemas de biovigilancia lleve a muchas a defender un retorno a la vida analógica y al encuentro local y cuerpo a cuerpo, como escapatoria a los riesgos de la interfaz tecnológica. Las experiencias de lucha y organización colectiva en los más recientes tiempos interpandémicos, desde Hong Kong hasta Santiago de Chile, pasando por las favelas de Brasil, nos han enseñado que esta 
sería, en realidad, una falsa alternativa. En la nueva normalidad, no habrá ni repliegue en el hogar ni nostalgia analógica posible: la resistencia será viral, o no será.

\section{Referencias}

ALTO COMISIONADO DE LAS NACIONES UNIDAS PARA LOS REFUGIADOS - ACNUR. La crisis de la COVID-19 subraya la necesidad de solidaridad e inclusión de las personas refugiadas. 7 oct. 2020. Disponible en: https://www.acnur.org/noticias/ noticia/2020/10/5f7f2c389/la-crisis-de-la-covid-19-subraya-lanecesidad-de-solidaridad-e-inclusion.html. Accedido: 20 oct. 2020. AGAMBEN, Giorgio. Homo sacer. El poder soberano y la vida nuda. Valencia: Pre-Textos, 1999.

AGAMBEN, Giorgio. La invención de una epidemia. In: AGAMBEN, Giorgio et al. Sopa de Wuhan: pensamiento contemporáneo en tiempos de pandemias. Buenos Aires: Aislamiento Social Preventivo y Obligatorio, 2020. p. 17-21.

ASSOCIAÇÃO NACIONAL DE TRAVESTIS E TRANSEXUAIS - ANTRA. Assassinatos de pessoas trans voltam a subir em 2020. 2020. Disponible en: https://antrabrasil.org/2020/05/03/assassinatos-de-pessoas-trans-voltam-a-subir-em-2020/. Accedido: 20 oct. 2020.

BAUDRILLARD, Jean. Réquiem para las Twin Towers. Summa+, Buenos Aires, n. 54, p. 36-39, 2002.

BENNHOLD, Katrin. Por qué la tasa de mortalidad de Alemania es tan baja. 6 abr. 2020. Disponible en: https://www.nytimes. com/es/2020/04/06/espanol/mundo/Alemania-tasa-mortalidadvirus.html. Accedido: 20 oct. 2020.

BRADBURY-JONES, Caroline; ISHAM, Louise. The pandemic paradox: the consequences of COVID-19 on domestic violence. Journal of Clinical Nursing, Oxford, v. 19, p. 2047-2049, 2020. 
BUTLER, Judith. Vida precaria: el poder del duelo y la violencia. Madrid: Paidós, 2006.

BUTLER, Judith. El capitalismo tiene sus límites. In: AGAMBEN, Giorgio et al. Sopa de Wuhan: pensamiento contemporáneo en tiempos de pandemias. Buenos Aires: Aislamiento Social Preventivo y Obligatorio, 2020. p. 59-67.

BYUNG-CHUL, Han. La emergencia viral y el mundo de mañana. In: AGAMBEN, Giorgio et al. Sopa de Wuhan: pensamiento contemporáneo en tiempos de pandemias. Buenos Aires: Aislamiento Social Preventivo y Obligatorio, 2020. p. 97-113.

CARRARA, Sérgio. As ciências humanas e sociais entre múltiplas epidemias. Revista de Saúde Coletiva, Rio de Janeiro, v. 30, n. 2, p. 1-6, 2020.

CENTER FOR DISEASE CONTROL AND PREVENTION - CDC. Disease burden of influenza. $17 \mathrm{abr}$. 2020a. Disponible en: https://www.cdc.gov/flu/about/burden/index.html. Accedido: 20 oct. 2020.

CENTER FOR DISEASE CONTROL AND PREVENTION - CDC. COVID-19 pandemic planning scenarios. 10 sep. $2020 \mathrm{~b}$. Disponible en: https://www.cdc.gov/coronavirus/2019-ncov/hcp/ planning-scenarios.html. Accedido: 10 sep. 2020.

CENTRE FOR EVIDENCE-BASED MEDICINE - CEBM. Global COVID-19 case fatality rates. 9 jun. 2020. Disponible en: https:// www.cebm.net/covid-19/global-covid-19-case-fatality-rates/. Accedido: 20 oct. 2020.

COMISIÓN ECONÓMICA PARA AMÉRICA LATINA Y EL CARIBE CEPAL. COVID-19 tendrá graves efectos sobre la economía mundial e impactará a los países de América Latina y el Caribe. 19 mar. 2020. Disponible en: https://www.cepal.org/es/ comunicados/covid-19-tendra-graves-efectos-la-economia-mundial-impactara-paises-america-latina. Accedido: 20 oct. 2020. 
CONFEDERACIÓN DE COMUNIDADES INDÍGENAS DEL ECUADOR CONAIE. Llamamiento de los pueblos originarios, afrodescendientes y las organizaciones populares de América Latina. 6 abr. 2020. Disponible en: https://conaie.org/2020/04/06/llamamiento-de-los-pueblos-originarios-afrodescendientes-y-las-organizaciones-populares-de-america-latina/. Accedido: 20 oct. 2020.

DELEUZE, Gilles. Postscript on the societies of control. October, Boston, v. 59, p. 3-7, 1992.

DELICADO, Ana; GONÇALVES, Maria Eduarda. Os portugueses e os novos riscos. Análise Social, Lisboa, n. 184, p. 687-718, 2007.

DERRIDA, Jacques. Autoimmunity: real and symbolic suicides. A dialogue with Jacques Derrida. In: BORRADORI, Giovanna. (org.). Philosophy in a time of terror: dialogues with Jürgen Habermas and Jacques Derrida. Chicago: The University of Chicago Press, 2003. p. 85-136.

EL PAÍS. Duterte ordena disparar contra quien viole la cuarentena. 2 abr. 2020. Disponible en: https://elpais.com/internacional/2020-04-02/duterte-ordena-disparar-contra-quien-viole-la-cuarentena.html. Accedido: 20 oct. 2020.

ESPOSITO, Roberto. Immunitas. Protección y negación de la vida. Buenos Aires: Amorrortu, 2005.

EUROPEAN UNION AGENCY FOR FUNDAMENTAL RIGHTS - FRA. Coronavirus pandemic in the EU: fundamental rights implications. Luxembourg: Publications Office of the European Union, 2020.

FERGUSON, Neil M. et al. Impact of non-pharmaceutical interventions (NPIs) to reduce COVID-19 mortality and healthcare demand. 2020. Disponible en: https://doi.org/10.25561/77482. Accedido: 20 oct. 2020.

FORE, Henrietta H. A wake-up call: COVID-19 and its impact on children's health and wellbeing. The Lancet Global Health, 
London, v. 8, n. 7, e861-e862, 2020. Disponible en: https://doi. org/10.1016/S2214-109X(20)30238-2. Accedido: 20 oct. 2020.

FOUCAULT, Michel. The birth of the clinic. An archaeology of medical perception. London: Routledge, 1973.

FOUCAULT, Michel. Defender la sociedad. Curso en el Collège de France (1975-1976). Buenos Aires: Fondo de Cultura Económica, 2000.

FUENTECILLA, José Luis. Adolfo García-Sastre, virólogo: "el coronavirus infectará a más gente que la gripe y puede causar más de un millón de muertos en el mundo". 1 mar. 2020. Disponible en: https://www.niusdiario.es/sociedad/sanidad/adolfo-garcia-sastre-virologo-coronavirus-infectara-mas-gente-que-gripe-causara-millon-muertos-mundo_18_2906670177.html. Accedido: 20 oct. 2020.

GARCÍA, Jacobo. Bukele autoriza a la policía a matar pandilleros en El Salvador tras un sangriento fin de semana. $27 \mathrm{abr}$. 2020. Disponible en: https://elpais.com/internacional/2020-04-27/ bukele-autoriza-a-la-policia-a-emplear-la-fuerza-letal-contra-los-pandilleros.html. Accedido: 20 oct. 2020.

GLOBAL PREPAREDNESS MONITORING BOARD - GPMB. Un mundo en peligro. Informe anual sobre preparación mundial para las emergencias sanitarias. Geneva: GPMB, 2019a.

GLOBAL PREPAREDNESS MONITORING BOARD - GPMB. The state of governance and coordination for health emergency preparedness. Oxford: University of Oxford, 2019b.

HANCOCK, Matt. Statutory Instruments n. 588, 2020. Public Health, England. 2020. Disponible en: https://www.legislation.gov. uk/uksi/2020/558/pdfs/uksi_20200558_en.pdf. Accedido: 20 oct. 2020 .

HARDT, Michael; NEGRI, Antonio. Imperio. Barcelona: Paidós, 2002. 
HEALTH PROTECTION SURVEILLANCE CENTRE - HPSC. Influenza and other seasonal respiratory viruses in Ireland, 2017/2018. 2018. Disponible en: https://www.hpsc.ie/a-z/respiratory/influenza/seasonalinfluenza/surveillance/influenzasurveillancereports/ previousinfluenzaseasonssurveillancereports/20172018season/ Influenza\%202017-2018\%20Annual\%20Summary_Final.pdf. Accedido: 20 oct. 2020.

INSTITUTO DE SEGURANÇA PÚBLICA - ISP. Instituto de Segurança Pública divulga dados de abril. 26 mayo 2020. Disponible en: http://www.isp.rj.gov.br/Noticias.asp?ident=438. Accedido: 15 sep. 2020.

KASPERSON, Roger E. Six propositions on public participation and their relevance for risk communication. In: KASPERSON, J.; KASPERSON, R. E. (ed.). The social contours of risk: publics, risk communication and the social amplification of risk. London: Earthscan, 2005. v. 1, p. 19-28.

KITCHIN, Rob. Civil liberties or public health, or civil liberties and public health? Using surveillance technologies to tackle the spread of COVID-19. Space and Polity, London, v. 24, n. 3, p. 362$381,2020$.

KOBAYASHI, Tetsuro et al. Communicating the risk of death from novel Coronavirus Disease (COVID-19). Journal of Clinical Medicine, Basel, v. 9, n. 2, p. 580, 2020.

LIMA, Maria Luisa. Factores sociais na percepção de riscos. Psicologia, Lisboa, v. 12, n. 1, 1998.

LIPSITCH, Marc et al. Potential biases in estimating absolute and relative case-fatality risks during outbreaks. 16 jul. 2015. Disponible en: https://doi.org/10.1371/journal.pntd.0003846. Accedido: 20 oct. 2020.

\section{LLANERAS, Kiko. ¿Cómo se compara el coronavirus con la} gripe? Los números dicen que es peor. 3 mar. 2020. Disponible en: https://elpais.com/ciencia/2020-03-02/como-se-compara-el- 
coronavirus-con-la-gripe-los-numeros-dicen-que-es-peor.html. Accedido: 20 oct. 2020.

LÓPEZ-FONSECA, Óscar. Más de un millón de multas por burlar el confinamiento. 19 mayo 2020. Disponible en: https://elpais.com/ espana/2020-05-19/mas-de-un-millon-de-multas-por-burlar-elconfinamiento.html. Accedido: 20 oct. 2020.

MBEMBE, Achille. Necropolitics. Public Culture, Durham, v. 15, n. 1, p. 11-40, 2003.

NIELSEN, J. et al. European all-cause excess and influenza-attributable mortality in the 2017/18 season: should the burden of influenza $B$ be reconsidered? Clinical Microbiology and Infection, London, v. 25, n. 10, p. 1266-1276, 2019.

ORGANISATION FOR ECONOMIC CO-OPERATION AND DEVELOPMENT - OECD. What is the impact of the COVID-19 pandemic on immigrants and their children? 2020. Disponible en: http://www.oecd.org/coronavirus/policy-responses/what-isthe-impact-of-the-covid-19-pandemic-on-immigrants-and-theirchildren-e7cbb7de/. Accedido: 20 oct. 2020.

ORGANIZACIÓN MUNDIAL DE LA SALUD - OMS. 7 millones de muertes cada año debidas a la contaminación atmosférica. 2014. Disponible en: https://www.who.int/mediacentre/news/releases/2014/air-pollution/es/. Accedido: 20 oct. 2020.

ORGANIZACIÓN MUNDIAL DE LA SALUD - OMS. 10 datos sobre la seguridad vial en el mundo. 2017. Disponible en: https://www. who.int/features/factfiles/roadsafety/es/. Accedido: 20 oct. 2017.

ORGANIZACIÓN MUNDIAL DE LA SALUD - OMS. El Informe Mundial sobre el Paludismo 2019 de un vistazo. 2019. Disponible en: https://www.who.int/malaria/media/world-malaria-report-2019/es/. Accedido: 20 oct. 2020.

ORGANIZACIÓN MUNDIAL DE LA SALUD - OMS. Tuberculosis. 2020. Disponible en: https://www.who.int/es/news-room/factsheets/detail/tuberculosis. Accedido: 20 oct. 2020. 
PAGET, John et al. Global mortality associated with seasonal influenza epidemics: new burden estimates and predictors from the GLaMOR Project. Journal of Global Health, Edinburgh, v. 9, n. 2, p. 1-12, 2019.

PEREZ-BRUMER, Amaya; SILVA-SANTISTEBAN, Alfonso. COVID-19 policies can perpetuate violence against transgender communities: insights from Peru. 2020. Disponible en: https://doi. org/10.1007/s10461-020-02889-z. Accedido: 20 oct. 2020.

PÉREZ NAVARRO, Pablo. Pandemia y orden público: el espacio de la protesta. Voluntas: Revista Internacional de Filosofia, Santa Maria, v. 11, n. 4, p. 1-8, 2020.

PRECIADO, Paul B. Testo Yonqui. Madrid: Espasa, 2008.

PRECIADO, Paul B. Aprendiendo del virus. 28 mar. 2020.

Disponible en: https://elpais.com/elpais/2020/03/27/opinion/1585316952_026489.html/. Accedido: 24 mar. 2021.

PROGRAMA CONJUNTO DE LAS NACIONES UNIDAS SOBRE EL VIH/ SIDA - ONUSIDA. Últimas estadísticas sobre el estado de la epidemia de sida. 2020. Disponible en: https://www.unaids.org/ es/resources/fact-shee. Accedido: 20 oct. 2020.

RUSSELL, Timothy W. et al. Estimating the infection and case fatality ratio for coronavirus disease (COVID-19) using age-adjusted data from the outbreak on the Diamond Princess cruise ship, February 2020. Eurosurveillance, Stockholm, v. 25, n. 12, p. 6-10, 2020.

SINHA, lan P. et al. COVID-19 infection in children. The Lancet Respiratory Medicine, London, v. 8, n. 5, p. 446-447, 2019.

SØREIDE, K. et al. Immediate and long-term impact of the COVID-19 pandemic on delivery of surgical services. $30 \mathrm{abr}$. 2020. Disponible en: https://doi.org/10.1002/bjs.11670. Accedido: 20 oct. 2020.

STANOJLOVIC, Milena. Percepción social de riesgo: una mirada general y aplicación a la comunicación de salud. Revista de Comunicación y Salud, Madrid, n. 5, p. 99-110, 2015. 
STOP TB PARTNERSHIP. The potential impact of the COVID-19 response on tuberculosis in high-burden countries: a modelling analysis. 2020. Disponible en: http://www.stoptb.org/assets/documents/news/Modeling Report_1 May 2020_FINAL.pdf. Accedido: 20 oct. 2020.

STREECK, Hendrick et al. Preliminary result and conclusions of the COVID-19 case cluster study (Gangelt Municipality). 9 abr. 2020. Disponible en: https://www.land.nrw/sites/default/files/asset/ document/zwischenergebnis_covid19_case_study_gangelt_en.pdf. Accedido: 20 oct. 2020.

THOMPSON, Dana-Claudia et al. The impact of COVID-19 pandemic on long-term care facilities worldwide: an overview on international issues. 11 nov. 2020. Disponible en: https://doi. org/10.1155/2020/8870249. Accedido: 24 mar. 2021.

TORALES, Julio et al. The outbreak of COVID-19 coronavirus and its impact on global mental health. International Journal of Social Psychiatry, London, v. 66, n. 4, p. 317-320, 2020.

\section{8}

VALENTE, Jonas. COVID-19: Brasil tiene 374.898 casos confirmados y 23.473 muertes. 26 mayo 2020. Disponible en: https:// agenciabrasil.ebc.com.br/es/saude/noticia/2020-05/covid-19-brasil-tiene-374898-casos-confirmados-y-23473-muertes. Accedido: 20 oct. 2020.

VERITY, Robert et al. Estimates of the severity of Coronavirus Disease 2019: a model-based analysis. The Lancet. Infectious Diseases, London, n. 20, p. 669-677, 2020.

ZIZEK, Slavoj. Coronavirus es un golpe al capitalismo al estilo de 'Kill Bill' y podría conducir a la reinvención del comunismo. In: AGAMBEN, Giorgio et al. Sopa de Wuhan: pensamiento contemporáneo en tiempos de pandemias. Buenos Aires: Aislamiento Social Preventivo y Obligatorio, 2020. p. 21-29. 